\title{
An improved HPLC method for the quantitation of 6-mercaptopurine and its metabolites in red blood cells
}

B.M. Oliveira ${ }^{1}$, A.J. Romanha ${ }^{2}$, T.M.A. Alves ${ }^{3}$, M.B. Viana ${ }^{1}$ and C.L. Zani ${ }^{3}$

\author{
${ }^{1}$ Departamento de Pediatria, Faculdade de Medicina, \\ Universidade Federal de Minas Gerais, Belo Horizonte, MG, Brasil \\ Laboratórios de ${ }^{2}$ Parasitologia Celular e Molecular, and \\ ${ }^{3}$ Química de Produtos Naturais, Centro de Pesquisas René Rachou, \\ FIOCRUZ, Belo Horizonte, MG, Brasil
}

\section{Correspondence \\ C.L. Zani \\ Laboratório de Química de Produtos \\ Naturais \\ Centro de Pesquisas René Rachou \\ FIOCRUZ \\ Av. Augusto de Lima, 1715 \\ 30190-002 Belo Horizonte, MG \\ Brasil \\ Fax: $+55-32-3295-3115$ \\ E-mail: zani@cpqrr.fiocruz.br}

Research supported by FIOCRUZ, CNPq, PRONEX and FAPEMIG.

Received July 15, 2003

Accepted March 16, 2004

\section{Abstract}

A procedure is described for the rapid determination of the intraerythrocyte concentration of 6-mercaptopurine (6-MP) and its metabolites, 6-thioguanine nucleotides (6-TGN) and 6-methylmercaptopurine (6-MMP). Erythrocytes $\left(8 \times 10^{8}\right.$ cells) in $350 \mu$ l Hanks solution containing $7.5 \mathrm{mg}$ dithiothreitol were treated with $50 \mu 170 \%$ perchloric acid. The precipitate was removed by centrifugation $(13,000 \mathrm{~g})$ and the supernatant hydrolyzed at $100^{\circ} \mathrm{C}$ for $45 \mathrm{~min}$. After cooling, $100 \mu \mathrm{l}$ was analyzed directly by HPLC using a Radialpack Resolve C18 column eluted with methanol-water $(7.5: 92.5, \mathrm{v} / \mathrm{v})$ containing 100 $\mathrm{mM}$ triethylamine. 6-TG, 6-MP and the hydrolysis product of 6-MMP, 4-amino-5-(methylthio)carbonyl imidazole, were monitored at 342, 322 and $303 \mathrm{~nm}$ using a Shimadzu SPD-M10A diode array UV detector. The analytes eluted at 5.3, 6.0 and $10.2 \mathrm{~min}$, respectively. The calibration curves were linear $\left(\mathrm{r}^{2}>0.998\right)$, and the analytical recoveries were $73.2 \%$ for $6-\mathrm{TG}, 119.1 \%$ for 6 -MP and $97.4 \%$ for 6 MMP. The intra- and inter-assay variations were highest for 6-MP (9.6 and $14.3 \%$, respectively). The lowest detectable concentrations were 3,3 and $25 \mathrm{pmol} / 8 \times 10^{8}$ erythrocytes for 6-TG, 6-MP and 6-MMP, respectively. The quantification limits (coefficients of variation $<15 \%$ ) were 8,10 and $70 \mathrm{pmol} / 8 \times 10^{8}$ erythrocytes for 6-TG, 6-MP and 6MMP, respectively. The method was applied to the analysis of 183 samples from 36 children under chemotherapy for acute lymphoblastic leukemia. The concentrations of the metabolites in the red cells of the patients ranged from 0 to $1934 \mathrm{pmol} / 8 \times 10^{8}$ erythrocytes for 6 TGN, and from 0 to 105.8 and 0 to $45.9 \mathrm{nmol} / 8 \times 10^{8}$ erythrocytes for 6-MP and 6-MMP, respectively. The procedure gave results that were in agreement with those obtained with other methods designed to detect cases of non-compliance with treatment, including patient interviews and medical evaluation, among others, demonstrating its applicability to monitoring the treatment of leukemic children.
Key words

- Acute lymphoblastic

leukemia

- Chemotherapy

- 6-Mercaptopurine

- Compliance

- Children 


\section{Introduction}

Acute lymphoblastic leukemia (ALL) is the most common malignancy affecting children. Prior to the discovery and application of chemotherapeutic agents, the majority of children suffering from ALL survived for only one or two months after diagnosis (1). However, over the last 30 years there has been a significant improvement in the prognosis of such patients and, currently, 70 to $80 \%$ of recently diagnosed children in developed countries present disease-free survival for more than 5 years, and most will eventually be cured (2). Treatment failures may be attributed to several factors, a major one being lack of adhesion to the prescribed treatment (3). Procedures to assess compliance with treatment, especially with respect to the effective delivery of chemotherapy, are of great importance to ALL patients and can even determine the outcome of the disease. Such assessments may be carried out by various indirect methods including patient interviews, medical evaluation, drug audits, etc. (4), although more direct methods involving quantitation of the drug and its metabolites in urine and erythrocytes have been proposed (5-9).

6-Mercaptopurine (6-MP), a chemotherapeutic agent commonly used to treat ALL, is an analogue of the natural nucleoside hypoxanthine. As is the case for the majority of

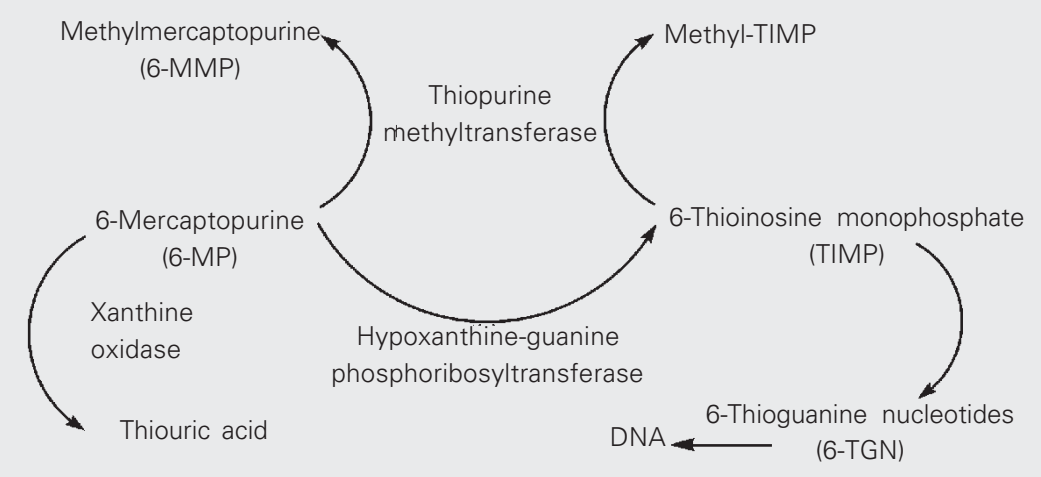

Figure 1. Schematic representation of the metabolism of 6-mercaptopurine (adapted from Refs. 10 and 37). purine analogues, 6-MP is a pro-drug and must be converted into the nucleotide by intracellular enzymes in order to exert its cytotoxic effects (10). Such conversion after oral administration of the drug follows three competing routes (Figure 1) $(11,12)$. One route occurs both in the intestinal mucosa and in the liver and involves the enzyme xanthine oxidase, which transforms 6-MP into thiouric acid, an inactive metabolite (10). A second route generates the active metabolite 6-thioinosine monophosphate (TIMP) by the action of the enzyme hypoxanthine-guanine phosphoribosyltransferase (10). This transformation results in the formation of active nucleotides including nucleotides of 6-thioguanine (6-TGN). The incorporation of 6-TGN into DNA and RNA is considered to be the principal mechanism of action of 6-MP (13). The third route is catalyzed by the enzyme thiopurine methyltransferase (TPMT), which converts 6-MP into 6methylmercaptopurine (6-MMP) (13). Despite some views to the contrary, this methylation is considered to be an inactivation mechanism since 6-MMP seems to be inactive (13). However, while the metabolism of 6-MP by TPMT reduces the formation of active 6-TGN (14), this enzyme is also responsible for the formation of methyl-TIMP, a metabolite that seems to be important for the cytotoxic activity of 6-MP as it may inhibit the de novo synthesis of purines (13). Significant differences in the activity of TPMT may be observed between individuals, thus accounting for the reported (15) differences in susceptibility to treatment with 6-MP. Studies among different populations and families have demonstrated a genetic autosomal co-dominant polymorphism of TPMT: thus, ca. $90 \%$ of Caucasians and Afro-Americans present high enzymatic activity, $10 \%$ present intermediate activity, and 1 in 300 individuals inherits deficient TPMT activity $(16,17)$.

The most important metabolites of 6-MP, the 6-TGNs, slowly accumulate in red cells and reach a steady-state concentration within 
1 to 4 weeks after the beginning of treatment (18). These metabolites are rapidly incorporated into the DNA and RNA of leukemic cells, leukocytes and their precursors in the bone marrow, thus making their detection somewhat difficult (19). However, the erythrocytes act as reservoirs of these metabolites since they do not synthesize nucleic acids, and the intra-erythrocyte TGN concentration, which reflects this accumulation following multiple doses of 6-MP (20), has been proposed as a useful parameter with which to monitor 6-MP maintenance chemotherapy (21-23). It should be emphasized, however, that this parameter alone may not be sufficient to optimize the treatment of some patients with ALL, and the concomitant evaluation of TPMT activity and leukocyte levels has been recommended in order fully to monitor the chemotherapy (24).

The majority of the methods for the quantitation of 6-MP metabolites involve the hydrolysis of nucleotides to the corresponding bases that can then be separated by HPLC and detected by UV absorption. During hydrolysis, 6-MMP is converted completely into 4-amino-5-(methylthio)carbonyl imidazole (AMTCI) (25) which, unlike 6-MMP, can be quantified by HPLC-UV under the same conditions as employed for the bases: the concentration of AMTCI thus determined correlates directly with that of the 6-MMP originally present (26).

We describe a quantitation procedure based on the publications of Dervieux and Boulieu (27) and Lennard and Singleton (26), which permits the rapid quantitation of the intraerythrocyte levels of 6-MP, 6-TGN and 6MMP. The method has been fully validated and employed to monitor 36 children with ALL receiving chemotherapy with 6-MP.

\section{Material and Methods}

\section{Chemicals}

Dithiothreitol (DTT), 6-thioguanine (6-
TG), 6-MP, and 6-MMP were purchased from Sigma; perchloric acid was from Carlo Erba and Hank's balanced salt solution was from Gibco BRL; triethylamine, phosphoric acid and all other chemicals were purchased in analytical grade from Merck (Rio de Janeiro, RJ, Brazil). Grade I water was produced from glass-distilled water using a MilliQ-UF Plus (Millipore, Molshein, France) system. All glassware was treated with $30 \%$ nitric acid for at least $12 \mathrm{~h}$ and then rinsed thoroughly with water.

\section{Patient selection}

The project was approved by the Ethics Committee of Research on Human Beings of the Federal University of Minas Gerais (COEP-UFMG 007/97). The children were included in the study only after their parents or guardians had been fully informed and had signed the terms of consent. The study population consisted of 36 patients aged less than 18 years, who had been diagnosed at UFMG from May 1997 to December 2000 to be suffering from ALL (as assessed by a bone marrow smear stained with MayGrünwald-Giemsa and confirmed by immunophenotyping) and had started the maintenance phase of the Brazilian therapeutic protocol GBTLI-93. The recommended dosage of 6-MP for this group of patients was $50 \mathrm{mg}$ $\mathrm{m}^{-2}$ day $^{-1}$ but was adjusted for each child according to the leukocyte count and the presence of clinically relevant infections: retrospectively, the mean dosage prescribed ranged from 24.6 to 66.9 (median 46.1) $\mathrm{mg}$ $\mathrm{m}^{-2}$ day $^{-1}$. Blood samples for the assay of 6MP metabolites were collected from the eighth week of the maintenance phase of treatment and at intervals of approximately 8 weeks thereafter. Patients should have been under continuous administration of 6-MP for a minimum period of 4 weeks and should not have received packed red cell transfusions in the 6 weeks preceding blood sample collection. Two to six samples were ob- 
tained from each patient (providing a total of 183 samples for the entire population) according to the extent of the maintenance phase of treatment. The samples were coded and the identities of the patients were not revealed until the quantitation data and the answers given in the patients' questionnaires were analyzed at the same time.

\section{Preparation of clinical samples}

Whole blood was collected in ethylenediaminetetraacetic acid (EDTA) as anticoagulant, and red blood cells were separated by centrifugation at $160 \mathrm{~g}$ for $10 \mathrm{~min}$ at $4^{\circ} \mathrm{C}$. The platelet-rich supernatant plasma and the buffy coat containing leukocytes and platelets were discarded, and the pellet was washed

Table 1. Precision and accuracy of the determination of intra-erythrocyte concentrations of 6-MP, 6-TG and 6-MMP.

\begin{tabular}{|c|c|c|c|c|}
\hline \multirow{2}{*}{$\begin{array}{l}\text { Metabolites } \\
\text { in standard } \\
\text { samples }\end{array}$} & \multirow{2}{*}{$\begin{array}{l}\text { Amount added } \\
\text { (pmol) }\end{array}$} & \multirow{2}{*}{$\begin{array}{l}\text { Amount found (pmol) } \\
\text { (\% of amount added) }\end{array}$} & \multicolumn{2}{|c|}{ Coefficient of variation (\%) } \\
\hline & & & $\begin{array}{c}\text { Intra-assay } \\
\quad(N=3)\end{array}$ & $\begin{array}{l}\text { Inter-assay } \\
(N=10)\end{array}$ \\
\hline \multicolumn{5}{|l|}{ 6-MP } \\
\hline 1 & 200 & 207 (104) & 5.6 & - \\
\hline 2 & 160 & 164 (103) & 1.2 & 10.4 \\
\hline 3 & 120 & $118(98)$ & 9.6 & - \\
\hline 4 & 80 & 78 (98) & 1.9 & 14.3 \\
\hline 5 & 40 & $40(100)$ & 7.8 & 13.6 \\
\hline 6 & 20 & $23(115)$ & 1.1 & - \\
\hline \multicolumn{5}{|l|}{$6-\mathrm{TG}$} \\
\hline 1 & 1230 & $1222(99)$ & 5.9 & - \\
\hline 2 & 820 & $830(101)$ & 2.9 & 4.0 \\
\hline 3 & 410 & 424 (103) & 2.6 & - \\
\hline 4 & 246 & $239(97)$ & 5.4 & 2.1 \\
\hline 5 & 164 & $166(101)$ & 4.1 & 7.5 \\
\hline 6 & 82 & 89 (108) & 0.9 & - \\
\hline \multicolumn{5}{|l|}{ 6-MMP } \\
\hline 1 & 24000 & $24340(101)$ & 5.2 & - \\
\hline 2 & 12000 & $12150(101)$ & 1.4 & 6.2 \\
\hline 3 & 6000 & $6070(101)$ & 4.6 & - \\
\hline 4 & 3000 & 2970 (99) & 1.0 & 6.7 \\
\hline 5 & 1500 & $1520(101)$ & 5.5 & 14.3 \\
\hline 6 & 750 & $830(110)$ & 4.0 & - \\
\hline
\end{tabular}

The erythrocytes $\left(8 \times 10^{8}\right)$, obtained from healthy volunteers, were suspended in 200 $\mu \mathrm{l}$ Hanks solution and spiked with the indicated amount of the metabolites. Extraction, hydrolysis and HPLC analysis were performed as described in Methods. The amount found was back-calculated from the calibration curve. For abbreviations, see Figure 1. with two volumes of Hanks solution and centrifuged at $160 \mathrm{~g}$ for $10 \mathrm{~min}$ at $4^{\circ} \mathrm{C}$. Again, the supernatant was discarded and the erythrocytes were suspended in Hanks solution at a density of $8 \times 10^{8}$ erythrocytes/ $200 \mu 1$. This suspension was kept at $-20^{\circ} \mathrm{C}$ until required for further processing (28).

\section{Preparation of standard mixtures}

Stock solutions of 6-TG and 6-MMP at concentrations of 185.6 and $242.4 \mu \mathrm{g} / \mathrm{ml}$, respectively, were prepared by dissolving the appropriate amount of weighed standard in $1 \mathrm{ml}$ of $0.1 \mathrm{M} \mathrm{NaOH}$, diluting with $21 \mathrm{ml}$ water and acidifying with $2.5 \mathrm{ml}$ of $0.1 \mathrm{M}$ $\mathrm{HCl}$. A stock solution of $208.0 \mu \mathrm{g} / \mathrm{ml}$ 6-MP was prepared by dissolving the appropriate amount of weighed standard in $1 \mathrm{ml}$ of $0.1 \mathrm{M}$ $\mathrm{NaOH}$ and completing the volume to $25.0 \mathrm{ml}$ with water. The stock solutions were used to prepare six standard mixtures with different concentrations of metabolites by dilution as appropriate with $0.1 \mathrm{M} \mathrm{HCl}$ containing 154 $\mathrm{mg} / \mathrm{ml}$ DTT. Aliquots $(1 \mathrm{ml})$ of these standard mixtures were transferred to $1.5 \mathrm{ml}$ microcentrifuge tubes and stored at $-20^{\circ} \mathrm{C}$.

\section{Preparation of standard samples}

A 50- $\mu 1$ aliquot of each of the six standard mixtures (see Table 1) was added to $200 \mu 1$ Hanks solution containing $8 \times 10^{8}$ erythrocytes obtained from healthy volunteers (who had been taking no medications) and processed as described for the clinical samples. The final concentrations of the metabolites in each of the six standard samples are shown in Table 1.

\section{Sample extraction and hydrolysis}

A procedure based on a published protocol (27) was employed. The erythrocyte suspension $(200 \mu \mathrm{l})$, together with DTT $(100 \mu \mathrm{l}$ of solution containing $75 \mathrm{mg} / \mathrm{ml}$ ) and water $(50 \mu \mathrm{l})$ were added to an Eppendorf tube 
held in an ice bath. Following homogenization, the suspension was treated with $70 \%$ perchloric acid $(50 \mu 1)$, mixed with a vortex mixer for $30 \mathrm{~s}$, and centrifuged at 13,000 $\mathrm{g}$ for $15 \mathrm{~min}$ at room temperature. The supernatant $(300 \mu \mathrm{l})$ was transferred to a $2-\mathrm{ml}$ vial closed with a Teflon-lined screw cap, and heated at $100^{\circ} \mathrm{C}$ for $45 \mathrm{~min}$ to hydrolyze the nucleotides and also to generate AMTCI from 6-MMP (25). Hydrolyzed samples were stored in an ice bath, and aliquots $(100 \mu \mathrm{l})$ were injected into the HPLC apparatus for analysis as described below.

\section{Chromatographic assay}

Standard mixtures, standard samples and clinical samples were analyzed by HPLC (26) using a Shimadzu HPLC system consisting of an LC-10AD solvent delivery pump, an FCV-10AL low pressure solvent selector valve and an SPD-M10A diode array UV detector: a Waters Radial-Pak Resolve C18 column $(100 \times 8 \mathrm{~mm} ; 5$ - $\mu \mathrm{m}$ particle size $)$ was mounted in a Waters RCM $8 \times 10$ radial compressor and protected by a Waters GuardPak Resolve C18 pre-column. Elution was with methanol-water $(7.5: 92.5, \mathrm{v} / \mathrm{v})$ containing $100 \mathrm{mM}$ triethylamine and adjusted to pH 3.2 with $0.1 \mathrm{M}$ phosphoric acid: immediately before analysis, DTT was added to the eluent to produce a $0.5-\mathrm{mM}$ solution that was purged with helium and pumped at a flow rate of $1.4 \mathrm{ml} / \mathrm{min}$. The column effluent was monitored simultaneously at $303 \mathrm{~nm}$ for AMTCI, at $322 \mathrm{~nm}$ for 6-MP and at $342 \mathrm{~nm}$ for 6-TG. The calibration curves and quantifications were based on the peak areas as determined using provided Shimadzu software (Class LC-10). After each day of use, the analytical column was washed with 60 $\mathrm{ml}$ of methanol and the guard-column was replaced after 300 injections.

\section{Assay validation}

Standard samples were used to deter- mine the analytical recovery, accuracy and precision of the method over the entire concentration range. The intra-assay variation was calculated from triplicate measurements at each concentration, while the inter-assay variation was obtained from experiments completed on 10 different days. The analytical recovery was calculated by comparing the HPLC peak areas of processed standard samples with processed and unprocessed standard mixtures.

\section{Results}

\section{HPLC chromatography}

Figure 2A shows an HPLC chromatogram of a processed blood sample obtained from an untreated healthy volunteer: after the first $4.3 \mathrm{~min}$ of elution, no peaks could be detected at 303, 322 or $342 \mathrm{~nm}$. Figure 2B depicts the HPLC chromatogram of a processed standard mixture showing peaks of 6TG (detected at $342 \mathrm{~nm}$ ), 6-MP (at $322 \mathrm{~nm}$ ) and AMTCI (at $303 \mathrm{~nm}$; corresponding to 6MMP in the original mixture) eluting at 5.3, 6.0 and $10.2 \mathrm{~min}$, respectively. The limits of detection (signal-to-noise ratio of 5) were 3 pmol for 6-TG and 6-MP, and 25 pmol for AMTCI/6-MMP, whereas the limits of quantification (LOQ; coefficient of variation $<15 \%$ ) were 8 pmol for $6-\mathrm{TG}, 10 \mathrm{pmol}$ for $6-$ MP, and 70 pmol for AMTCI/6-MMP). Values below the LOQ were interpreted as showing the absence of the metabolite. In order to determine the shelf life of the standard mixtures, the mixtures were stored at $-20^{\circ} \mathrm{C}$ during the study period (20 months) and showed unchanged HPLC profiles when re-analyzed after this time.

\section{Assay validation}

The calibration curves constructed using standard samples were linear and the correlation coefficients $\left(\mathrm{r}^{2}\right)$ were $0.9992,0.9904$ and 0.9998 for 6-TG, 6-MP and AMTCI/6- 
MMP, respectively: typical equations were, respectively, $y=146.4 x, y=210.2 x+3378.3$ and $y=115552 x+215099$, where $y$ is the area under the peak and $x$ the concentration of metabolite (pmol/8 x $10^{8}$ erythrocytes). The intra-assay coefficients of variation
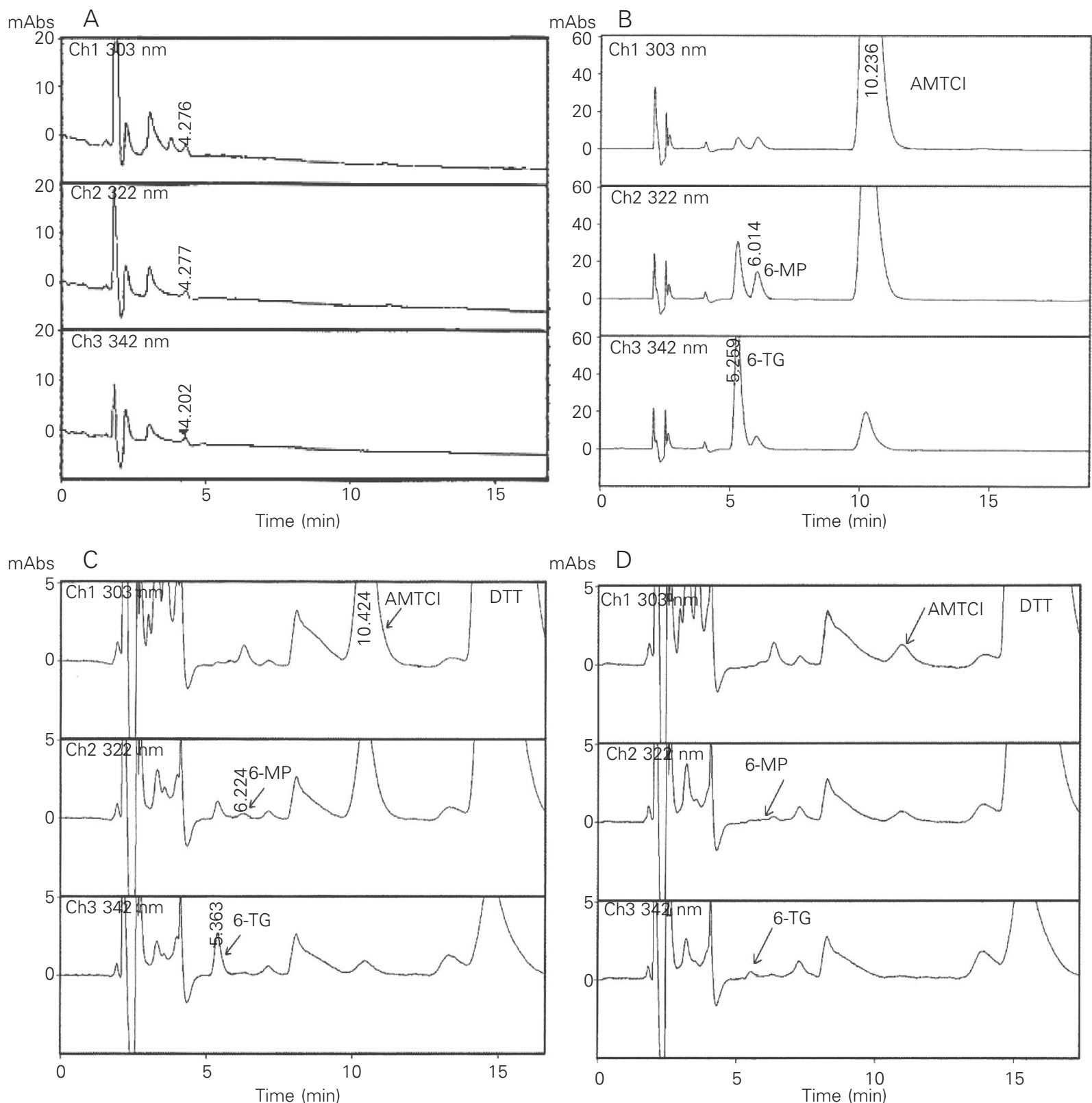

Figure 2. A, HPLC elution diagrams of a blood sample obtained from a healthy volunteer which was processed and then analyzed by HPLC using a Radial-Pak Resolve C18 column $(100 \times 8 \mathrm{~mm} ; 5 \mu \mathrm{m}$ particle size, eluted with methanol-water $(7.5: 92.5, \mathrm{v} / \mathrm{v})$ containing $100 \mathrm{mM}$ triethylamine adjusted to $\mathrm{pH} 3.2$ with phosphoric acid; the flow rate was $1.4 \mathrm{ml} / \mathrm{min}$; detection was by a photodiode array with channel 1 at $303 \mathrm{~nm}$, channel 2 at $322 \mathrm{~nm}$, and channel 3 at $342 \mathrm{~nm}$. B, HPLC chromatogram of standard mixture 2 (see Table 1). Sample processing and HPLC analysis were as described in $A$. C, HPLC chromatogram of a blood sample collected from a patient using 6-MP at a dose rate of $47.8 \mathrm{mg} \mathrm{m}^{-2}$ day ${ }^{-1}$. Sample processing and HPLC analysis were as described in $A$. D, HPLC chromatogram of a blood sample from the same patient as in $C$ who had missed taking 6 -MP at a dose rate of 58.1 $\mathrm{mg} \mathrm{m}^{-2}$ day ${ }^{-1}$, showing low levels of the metabolites 6-TG and MMP (AMTCI). Sample processing and HPLC analysis were as described in A. AMTCI = 4-amino-5-(methylthio)carbonyl imidazole; DTT = dithiothreitol. For other abbreviations, see Figure 1. 
ranged from 0.9 to $9.6 \%$ and inter-assay coefficients of variation were 2.1 to $14.3 \%$. When compared with the processed standard mixture, the recoveries of the metabolites in processed standard samples were $73.2 \%$ for 6 -TG, $119.1 \%$ for 6 -MP and $97.4 \%$ for AMTCI/6-MMP: such recoveries were obtained only after the amount of DTT recommended to be added to the sample in the published protocol (27) was doubled. Prior to the analysis of each batch of clinical samples, the standard curve was validated using the standard samples 2, 4 and 5 (see Table 1) employed as quality controls for the method.

\section{Quantitation of metabolites in clinical samples}

The intra-erythrocyte concentrations of 6-TGN determined in the blood samples of patients varied from 0 to 1934.0 (median 319.7; mean 372.1) pmol/8 x $10^{8}$ erythrocytes, from 0 to 105.8 (median 2.9; mean 13.9) $\mathrm{pmol} / 8 \times 10^{8}$ erythrocytes for 6-MP, and from 0 to 45.9 (median 6.3; mean 8.3) $\mathrm{nmol} / 8 \times 10^{8}$ erythrocytes for 6-MMP. Figure $2 \mathrm{C}$ illustrates the HPLC chromatogram of a sample obtained from a patient using 6MP at a dose of $47.8 \mathrm{mg} \mathrm{m}^{-2} \mathrm{day}^{-1}$. The peaks at 5.4 and $10.4 \mathrm{~min}$ correspond to 331.8 pmol 6-TGN/ $8 \times 10^{8}$ erythrocytes and to 4.7 nmol 6-MMP/8 x $10^{8}$ erythrocytes, respectively. The intense peak at $14.8 \mathrm{~min}$ is due to the DTT added to the sample. Figure 2D shows the HPLC chromatogram of the same patient having failed to take a prescribed dose of $58.1 \mathrm{mg} 6-\mathrm{MP} \mathrm{m}^{-2}$ day $^{-1}$; the peak at 5.4 min corresponds to $73.4 \mathrm{pmol} 6-\mathrm{TGN} / 8$ x $10^{8}$ erythrocytes while the peak at $10.4 \mathrm{~min}$ corresponds to $0.3 \mathrm{nmol} 6-\mathrm{MMP} / 8 \times 10^{8}$ erythrocytes. The peaks at $6.2 \mathrm{~min}$, corresponding to 6-MP, could not be quantified in either sample as they were below the LOQ. The non-compliance of this patient with the treatment indicated by the above result was confirmed by interviews and reports from medical charts (29).

\section{Discussion}

Several methods have been reported for the determination of 6-MP and its metabolites in biological fluids (30). The ideal method should allow the assessment of patient compliance with the treatment, together with measurement of the absorption, transport and accumulation of the cytotoxic metabolites (31). Studies concerning the quantification of 6-MP and its metabolites in the urine of patients showed that the main disadvantage of this type of sample is that it can detect failures in adherence to the treatment only when the analysis is performed shortly after the missed event (6). On the other hand, the quantitation of 6-MP and its metabolites in erythrocytes is more appropriate for the assessment of the regular use of the drug during long-term treatment as a steady state is reached (32) and should then be maintained.

In a method proposed by Lennard and Singleton (26), the nucleotides in a sample of erythrocytes are hydrolyzed and the bases extracted with phenyl mercuric acetate (PMA) and toluene. The hydrolysis method transforms the non-HPLC quantifiable metabolite 6-MMP to the quantifiable derivative AMTCI (25). However, the PMA-based procedure has several disadvantages in that it is laborious, uses a highly toxic reagent, and is not robust enough for use in many laboratories $(27,33)$. It was concluded (34) that the complexity of the technique poses serious difficulties to its use in large scale investigations. An alternative procedure (27) for hydrolysis and extraction was based on the use of $70 \%$ perchloric acid as both a deproteinizing and hydrolyzing agent, followed by direct injection into an HPLC apparatus and subsequent analysis. However, the chromatographic conditions used in the PMA-based procedure (26) are superior to those employed in the latter methodology in 
that they permit the simultaneous determination of 6-MP, 6-TG and AMTCI/6-MMP in erythrocytes. In the present study, we combined the extraction and hydrolytic procedure developed by Dervieux and Boulieu (27) with the HPLC protocol published earlier (26). The modified procedure permitted the simultaneous analysis of 6-MP and its metabolites 6-TGN and 6-MMP in smallvolume blood samples collected from children with ALL undergoing chemotherapy. The samples could be processed and analyzed by HPLC with isocratic elution in just $15 \mathrm{~min}$, thus making the procedure appropriate for the investigation of a large number of samples. Another possibility, not examined in the present study, is the suitability of the method for automation with the aim of increasing the reproducibility and the throughput of the assay.

The calibration curves for 6-MP, 6-TG and AMTCI/6-MMP were linear, with correlation coefficients greater than 0.998 . The intra-assay coefficients of variation were $<10 \%$ over the entire concentration range for all of the compounds analyzed, while the inter-assay variations were $<15 \%$ for 6 -MP and AMTCI/6-MMP and below 7.5\% for 6TG. Previous reports $(26,27)$ cite intra- and inter-assay variations below $10 \%$ for both 6 TG and 6-MMP at the two concentrations evaluated; the value for 6-MP, however, was not provided (26). In an earlier study (35), an intra-assay variation of more than $10 \%$ was reported for at least one point on the calibration curve for both 6-MP and 6-MMP. In the case of 6-TG, the variation was less than $10 \%$ at all points on the curve while the interassay variation was greater than $10 \%$ at one of the three concentrations monitored.

The analytical recoveries determined in the present investigation were $73.2 \%$ for 6 TG and $97.4 \%$ for 6-MMP, these values being similar to the previously reported values of 73.1 and $84 \%$ (27), 68.6 and $45 \%$ (26) and 74 and $\geq 38 \%$ (35), respectively. The LOQ values of 8,10 and 70 pmol in $8 \times 10^{8}$ erythrocytes $/ 200 \mu 1$ respectively determined for 6-TG, 6-MP and 6-MMP in this study, are slightly better than those obtained earlier (26) and those reported in Ref. 35 (30 pmol for 6-TG and $120 \mathrm{pmol}$ for 6-MMP). Other workers (34) have been able to achieve LOQ values of $18 \mathrm{pmol}$ for both 6-TG and 6MMP.

Our results show large differences in the intra-erythrocyte concentrations of 6-TG and 6-MMP in the samples analyzed. However, these intra- and inter-individual variations are similar to those reported by others $(8,9,26,36)$. The inter-individual differences seem to reflect individual differences in 6MP absorption and metabolism (due in part to the genetic polymorphism of TPMT) resulting in different bioavailability and distribution of the active metabolites in patients receiving similar doses. The variations observed in the values obtained for the same patient during a period of treatment suggest alternative explanations, among them the inadequate use of the prescribed medication (7) and non-compliance with treatment. Indeed, the aspect of non-compliance was also detected through questionnaires, interviews, and medical records (29), corroborating the observed low levels of drug and metabolites in erythrocytes of specific patients, and reinforcing the usefulness of this method in monitoring the treatment of children with ALL.

\section{Acknowledgments}

The authors wish to thank Rosana O. Alves for technical assistance and Marcelo E. de Lima Souza (Head of the Hematology Section, Laboratório Central do Hospital das Clínicas, UFMG) for training one of us (B.M. de Oliveira) in the preparation of the erythrocytes from blood samples. 


\section{References}

1. Beutler E (2001). The treatment of acute leukemia: past, present, and future. Leukemia, 15: 658-661.

2. Chessels JM (2000). Recent advances in management of acute leukemia. Archives of Disease in Childhood, 82: 438-442.

3. Pinkel D (1996). Selecting treatment for children with acute lymphoblastic leukemia. Journal of Clinical Oncology, 14: 4-6.

4. Wright EC (1993). Non-compliance - or how many aunts has Matilda? Lancet, 342: 909-913.

5. Azeemuddin S \& Bharmal FM (1988). Rapid method for evaluating compliance of 6-mercaptopurine therapy in children with leukemia. Journal of Chromatography, 430: 163-169.

6. MacDougall LG, McElligott SE, Ross E, Greeff MC \& Poole JE (1992). Pattern of 6-mercaptopurine urinary excretion in children with acute lymphoblastic leukemia: urinary assays as a measure of drug compliance. Therapeutic Drug Monitoring, 14: 371-375.

7. Davies HA, Lennard L \& Lilleyman JS (1993). Variable mercaptopurine metabolism in children with leukaemia: a problem of noncompliance? British Medical Journal, 306: 1239-1240.

8. Lennard L, Welch J \& Lilleyman JS (1995). Intracellular metabolites of mercaptopurine in children with lymphoblastic leukaemia: a possible indicator of non-compliance? British Journal of Cancer, 72: 1004-1006.

9. Lancaster D, Lennard L \& Lilleyman JS (1997). Profile of noncompliance in lymphoblastic leukaemia. Archives of Disease in Childhood, 76: 365-366.

10. Lennard $L$ (1992). The clinical pharmacology of 6-mercaptopurine. European Journal of Clinical Pharmacology, 43: 329-339.

11. Lennard L \& Lilleyman JS (1996). Individualizing therapy with 6mercaptopurine and 6-thioguanine related to the thiopurine methyltransferase genetic polymorphism. Therapeutic Drug Monitoring, 18: $328-334$

12. McLeod HL, Coulthard S, Thomas AE, Pritchard SC, King DJ, Richards SM, Eden OB \& Hall AG (1999). Analysis of thiopurine methyltransferase variant alleles in childhood acute lymphoblastic leukaemia. British Journal of Haematology, 105: 696-700.

13. Giverhaug $T$, Loennechen $T$ \& Aarbakke J (1999). The interaction of 6-mercaptopurine (6-MP) and methotrexate (MTX). General Pharmacology, 33: 341-346.

14. Lennard L, van Loon JA, Lilleyman JS \& Weinshilboum RM (1987). Thiopurine pharmacogenetics in leukemia: correlation of erythrocyte thiopurine methyltransferase activity and 6-thioguanine nucleotide concentrations. Clinical Pharmacology and Therapeutics, 41: 18-25.

15. Lennard L, Lilleyman JS, Loon JV \& Weinshilboum RM (1990). Genetic variation in response to 6-mercaptopurine for childhood acute lymphoblastic leukaemia. Lancet, 336: 225-229.

16. McLeod HL, Lin JS, Scott EP, Pui CH \& Evans WE (1994). Thiopurine methyltransferase activity in American white subjects and black subjects. Clinical Pharmacology and Therapeutics, 55: 15-20.

17. Weinshilboum RM \& Sladek SL (1980). Mercaptopurine pharmacogenetics: monogenic inheritance of erythrocyte thiopurine methyltransferase activity. American Journal of Human Genetics, 32: 651662.

18. Rostami-Hodjegan A, Lennard L \& Lilleyman JS (1995). The accumulation of mercaptopurine metabolites in age fractionated red blood cells. British Journal of Clinical Pharmacology, 40: 217-222.

19. Bostrom B \& Erdmann G (1993). Cellular pharmacology of 6-mercaptopurine in acute lymphoblastic leukemia. American Journal of
Pediatric Hematology/Oncology, 15: 80-86.

20. Balis FM, Holcenberg JS, Poplack DG et al. (1998). Pharmacokinetics and pharmacodynamics of oral methotrexate and mercaptopurine in children with lower risk acute lymphoblastic leukemia: A joint children's cancer group and pediatric oncology branch study. Blood, 92: 3569-3577.

21. Schmiegelow K \& Bruunshuus I (1990). 6-Thioguanine nucleotide accumulation in red blood cells during maintenance chemotherapy for childhood acute lymphoblastic leukemia, and it relation to leukopenia. Cancer Chemotherapy and Pharmacology, 26: 288-292.

22. Lennard L, Gibson BES, Nicole T \& Lilleyman JS (1993). Congenital thiopurine methyltransferase deficiency and 6-mercaptopurine toxicity during treatment for acute lymphoblastic leukaemia. Archives of Disease in Childhood, 69: 577-579.

23. Schmiegelow K, Schroder H, Gustafsson G, Kristinsson J, Glomstein A, Salmi T \& Wranne L (1995). Risk of relapse in childhood acute lymphoblastic leukemia is related to RBC methotrexate and mercaptopurine metabolites during maintenance therapy. Journal of Clinical Oncology, 13: 345-351.

24. Innocenti F, Danesi R, Favre C et al. (2000). Variable correlation between 6-mercaptopurine metabolites in erythrocytes and hematologic toxicity: Implications for drug monitoring in children with acute lymphoblastic leukemia. Therapeutic Drug Monitoring, 22: 375-382.

25. Dervieux T \& Boulieu R (1998). Identification of 6- methylmercaptopurine derivative formed during acid hydrolysis of thiopurine nucleotides in erythrocytes, using liquid chromatography-mass spectrometry, infrared spectroscopy, and nuclear magnetic resonance assay. Clinical Chemistry, 44: 2511-2515.

26. Lennard L \& Singleton HJ (1992). High-performance liquid chromatographic assay of the methyl and nucleotide metabolites of 6mercaptopurine: quantification of red blood cell 6-thioguanine nucleotide, 6-thioinosinic acid and 6-methylmercaptopurine metabolites in a single sample. Journal of Chromatography, 583: 83-90.

27. Dervieux T \& Boulieu R (1998). Simultaneous determination of 6thioguanine and methyl 6-mercaptopurine nucleotides of azathioprine in red blood cells by HPLC. Clinical Chemistry, 44: 551-555.

28. Lennard L (1987). Assay of 6-thioinosinic acid and 6-thioguanine nucleotides, active metabolites of 6-mercaptopurine, in human red blood cells. Journal of Chromatography, 423: 169-178.

29. Oliveira BM, Viana MB, Zani CL \& Romanha AJ (2004). Clinical and laboratory evaluation of compliance in acute lymphoblastic leukaemia. Archives of Disease in Childhood (in press).

30. Kato Y, Matsushita T, Yokoyama T \& Mohri K (1991). Determination of 6-mercaptopurine in acute lymphoblastic leukemia patients' plasma by high performance liquid chromatography. Therapeutic Drug Monitoring, 13: 220-225.

31. Rudy JL, Argyle JC, Winick N \& Van Dreal P (1988). HPLC analysis of 6-mercaptopurine and metabolites in extracellular body fluids. Annals of Clinical Biochemistry, 25: 504-509.

32. Davies HA \& Lilleyman JS (1995). Compliance with oral chemotherapy in childhood lymphoblastic leukaemia. Cancer Treatment Reviews, 21: 93-103.

33. Giverhaug $T$, Bergan $S$, Loennechen $T$, Rugstad HE \& Aarbakke $J$ (1997). Analysis of methylated 6-mercaptopurine metabolites in human red blood cells: Comparison of two methods. Therapeutic Drug Monitoring, 19: 663-668.

34. Mawatari H, Kato Y, Nishimura S-I, Sakura N \& Ueda K (1998). 
Reversed-phase high-perfomance liquid chromatographic assay method for quantitating 6-mercaptopurine and its methylated and non-methylated metabolites in a single sample. Journal of Chromatography, 716: 392-396.

35. Erdmann GR, France LA, Bostrom B \& Canafax DM (1990). A reversed phase high performance liquid chromatography approach in determining total red blood cell concentrations of 6-thioguanine, 6-mercaptopurine, methylthioguanine, and methylmercaptopurine in patient receiving thiopurine therapy. Biomedical Chromatography, 4: 47-51.
36. Relling MV, Hancock ML, Rivera GK, Sandlund JT, Ribeiro RC, Krynetski EY, Pui C-H \& Evans WE (1999). Mercaptopurine therapy intolerance and heterozygosity at the thiopurine S-methyltransferase gene locus. Journal of the National Cancer Institute, 91: 20012008.

37. McLeod HL, Krynetski EY, Relling MV \& Evans WE (2000). Genetic polymorphism of thiopurine methyltransferase and its clinical relevance for childhood acute lymphoblastic leukemia. Leukemia, 14: 567-572. 